\title{
Research on the Reclassification of Financial Assets
}

\section{Congcong Gou}

School of Financial Management, Sichuan University of Arts and Science, Chengdu, China

Email: gccghq@126.com

How to cite this paper: Gou, C.C. (2020) Research on the Reclassification of Financial Assets. Open Access Library Journal, 7: e6324. https://doi.org/10.4236/oalib.1106324

Received: April 14, 2020

Accepted: May 29, 2020

Published: June 2, 2020

Copyright (C) 2020 by author(s) and Open Access Library Inc.

This work is licensed under the Creative Commons Attribution International License (CC BY 4.0).

http://creativecommons.org/licenses/by/4.0/

\begin{abstract}
In order to better meet needs of the development of market economy, the Ministry of Finance revised the classification and transfer of financial assets in 2017, which would have a series of impacts on financial accounting after the revision. About how to implement the financial assets standard better, this paper uses comparative analysis, literature collection and other methods; combines with practical work to make a systematic study; analyzes the background of the revision, reclassification content and its impact. Through the research, it can be concluded that the reclassification of financial assets can reduce the use of accounting subjects, provide more reliable accounting information, and effectively prevent fraud. At the same time, after the reclassification, there are also problems such as subjectivity of business model judgment, uncertainty of fair value measurement, etc.
\end{abstract}

\section{Subject Areas}

Accounting, Business Finance and Investment

\section{Keywords}

New Accounting Standards, Financial Assets, Reclassification

\section{Introduction}

The implementation of the standards in 2006 played a positive role in standardizing the accounting treatment of financial instruments, promoting enterprises to strengthen the risk management, and improving the transparency of information disclosure of financial instruments. However, under the current social background, this standard no longer has practical significance, and even exposes a series of problems, such as the complex accounting treatment, lack of flexibility and high operating costs. It cannot adapt to the development of market econo- 
my. In order to solve the above problems effectively in a timely manner, the Ministry of Finance revised the financial instruments standard (hereinafter referred to as the New Related Accounting Standard of Financial instruments or the New Standard). This paper makes a comparative analysis on the classification and accounting of financial assets under the new and old accounting standards, finds out the differences Accounting standards for new and old financial instruments and their impact, and finally makes a deep analysis on financial assets under the new accounting standard, and explores the practical benefits of the revised new accounting standard for relevant enterprises.

\section{Content of Reclassification of Financial Assets}

The current "four categories" of financial assets are changed to "three categories". At present, in the current recognition and measurement standard of financial instruments, according to the reason why the owner holds the financial assets, financial assets are divided into four categories: financial assets measured at the fair value whose changes are included in the current profit and losses, held-to-maturity investment, loans and receivables, and available-for-sale financial assets. This classification method is very complex and not objective enough. The financial information about financial assets reflected in financial statements is quite comparative. In the newly issued accounting standard, the Ministry of Finance revised the recognition and measurement standard of financial instruments. Most importantly, it reclassified financial assets and used a completely different classification basis, i.e. the business model and cash flow characteristics of financial assets held by enterprises. Financial assets are divided into three categories: financial assets measured at the amortized cost, financial assets measured at the fair value whose changes are included in other comprehensive income, and financial assets measured at the fair value whose changes are included in the current profit and loss [1]. It should be noted that the non-tradable equity instrument investment designated by the company and the financial assets measured at the fair value whose changes are included in the current profit and loss cannot be cancelled or reclassified. The most obvious advantage of this classification method is to improve the objectivity of classification, and maintain the consistency of the method and the comparability of information in the accounting treatment.

\section{Analysis on the Reclassification of Financial Assets}

\subsection{Analysis of Account Setting under the New Standard}

Loans, receivables, available-for-sale financial assets or held-to-maturity investment cannot be reclassified as you like. If a certain type of assets is classified in the initial recognition, they cannot be changed in the subsequent treatment.

1) Financial assets measured at the amortized cost

In the classification of financial assets in the new and old standards, the held-to-maturity investment is classified as financial assets measured at the 
amortized cost. The main purpose is to reflect the investment of creditor's rights. The account setting of held-to-maturity investment in the current standard and the corresponding adjustments and changes of the account setting of financial assets measured at the amortized cost according to the changes in the new standard are shown in Table 1.

Through the above comparison, it can be found that for this kind of financial assets the reason for the change of its account setting is that the change of classification name causes the change of the corresponding ledger account. Its initial measurement, subsequent measurement and disposal are consistent and unchanged. Examples are as follows.

Company A purchased the bonds with the face value of RMB 100,000, a term of 5 years and the coupon rate of $6 \%$ whose interest was paid on December $31^{\text {st }}$ of each year issued by Company 1 on January $1^{\text {st }}, 2016$, and classified them as financial assets measured at the amortized cost. The actual purchase price (including the transaction expenses) was RMB 108,660, and the actual interest rate determined on the purchase day was $5 \%$. On December $10^{\text {th }}, 2018$, Company A decided to change the business model of managing the bonds of Company 1 . On December $31^{\text {st }}, 2018$, the book balance of bonds of Company 1 was RMB 103,720, including the cost of RMB 100,000 and the interest adjustment of RMB 3720. On the reclassification day (January $1^{\text {st }}, 2019$ ), the fair value of the bonds of Company 1 was RMB 109,000.

a) When Company A reclassified the bonds of Company 1 as financial assets measured at the fair value whose changes were included in the current profit or loss,

Debit: Tradable financial assets -- Bonds of Company 1 (cost) $\quad 109,000$

Credit: Investment of creditor's rights -- Bonds of Company 1 (cost) 100,000

-- Bonds of Company 1 (interest adjustment)

Profit and loss from changes in the fair value

b) When Company A reclassified the bonds of Company 1 as financial assets measured at the fair value whose changes were included in other comprehensive income,

Debit: Other investments of creditor's rights -- Bonds of Company 1 (cost)

--Bonds of Company 1 (interest adjustment)

100,000

--Bonds of Company 1 (change in the fair value)

Credit: Investment of creditor's rights-Bonds of Company 1 (cost)

--Bonds of Company 1 (interest adjustment)

100,000

Other comprehensive income-Changes in the fair value of other investments of creditor's rights

5280

Table 1. Changes in subjects of held-to-maturity investment.

\begin{tabular}{cr}
\hline & Account setting \\
\hline Current standard & Cost of held-to-maturity investment, accrued interest, interest adjustment \\
New accounting standard & Bond investment-cost, accrued interest, interest adjustment \\
\hline
\end{tabular}


2) Financial assets measured at the fair value whose changes are included in other comprehensive income

First, their name has been changed into financial assets measured at the fair value whose changes are included in other comprehensive income under the new standard. Second, the account setting varies by classification. When they are used as equity instrument and debt instrument, different accounting subjects are set. Non-tradable equity investment is financial assets measured at the fair value whose changes are included in other comprehensive income when they are acquired. It was designated by the company at the beginning and cannot be reclassified. Therefore, when it is treated, under the old standard the debit and credit subjects are set or the opposite accounting entry is set according to the actual situation. When the accounting treatment is made under the new standard, the debit and credit subjects are set, and the opposite subjects are set according to changes of conditions. The subjects set under the current standard for the account of available-for-sale financial assets, accounting subjects under different classifications of the new standard, and the comparison of subjects of the non-tradable equity investment under the new and old standards are shown in Table 2 .

It will be illustrated with the following example.

Company A purchased the bonds with the face value of RMB 600,000, a term of 5 years and the coupon rate of $8 \%$ whose interest was paid on December $31^{\text {st }}$ of each year issued by Company 2 on January $1^{\text {st }}, 2016$, and classified them as financial assets measured at the fair value whose changes were included in other comprehensive income. The actual purchase price (including the transaction expenses) was RMB 660,000, and the actual interest rate determined on the purchase day was $5.22 \%$. On December $5^{\text {th }}, 2018$, Company A decided to change the business model of managing the bonds of Company 2. On December $31^{\text {st }}, 2018$, the book balance of bonds of Company 2 was RMB 627,000, including the cost of RMB 600,000, the interest adjustment of RMB 21,200 and the change in the fair value of RMB 5800. On the reclassification day (January $1^{\text {st }}, 2019$ ), the fair value of the bonds of Company 2 was RMB 627,000.

a) When Company A reclassified the bonds of Company 2 as financial assets

Table 2. Changes in subjects of available-for-sale financial assets.

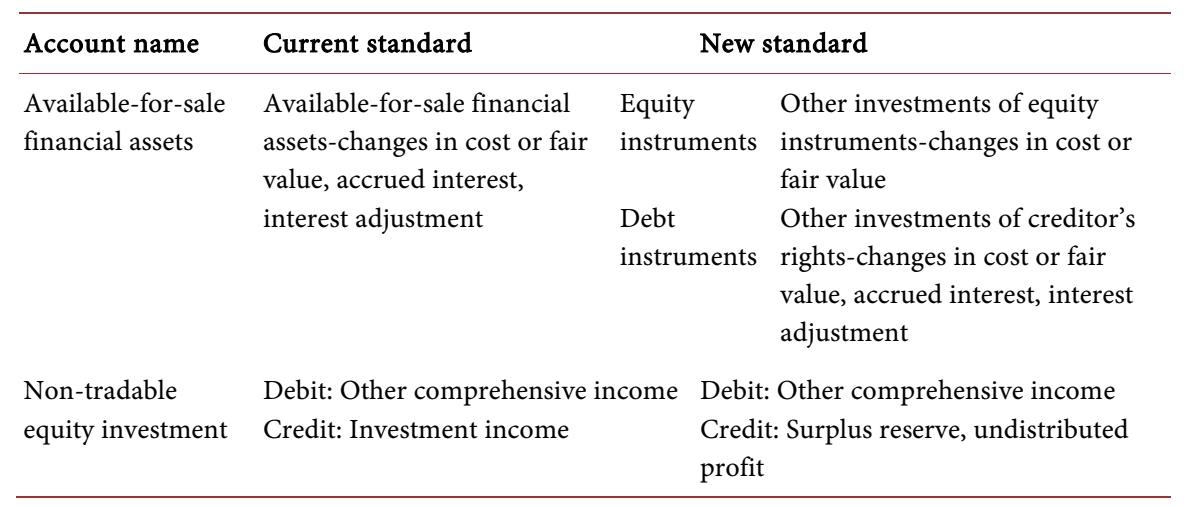


measured at the amortized cost,

Debit: Investment of creditor's rights -- Bonds of Company 2 (cost) 600,000

-- Bonds of Company 2 (interest adjustment) 21,200

Other comprehensive income -- Changes in the fair value of other investments of creditor's rights

5800

Credit: Other investments of creditor's rights -- Bonds of Company 2 (cost)

$$
\begin{array}{ll}
\text {-- Bonds of Company } 2 \text { (interest adjustment) } & 21,200 \\
\text {--Bonds of Company } 1 \text { (change in the fair value) } & 5800
\end{array}
$$

b) When Company A reclassified the bonds of Company 2 as financial assets measured at the fair value whose changes were included in the current profit and loss,

Debit: Tradable financial assets -- Bonds of Company 2 (cost)

627,000

Credit: Other investments of creditor's rights -- Bonds of Company 2 (cost) $6,000,000$

--Bonds of Company 2 (interest adjustment)

21,200

--Bonds of Company 1 (change in the fair value)

5800

Debit: Other comprehensive income-Changes in the fair value of other investments of creditor's rights

5800

Credit: Profit and loss from changes in the fair value

5800

3) Financial assets measured at the fair value whose changes are included in the current profit and loss.

This kind of financial assets are divided into tradable financial assets and financial assets designated to be measured at the fair value whose changes are included in the current profit and loss at the time of initial acquisition. Its corresponding account setting and accounting treatment are exactly the same as those under the original standard conditions, as shown in the figure below. There is no change. Changes in the fair value at the end of the current period are included in the current profit and loss [2]. The changes of other subjects are shown in the Table 3.

\subsection{Impact of the Reclassification of Financial Assets on Financial Statements}

The notice of standard issued by the Ministry of Finance in May 2017 meets the needs of relevant companies and management departments on the control of financial risks, and improves and enhances the transparency of business information of

Table 3. Changes in subjects of trading financial assets.

\begin{tabular}{ccc}
\hline & Current standard & New standard \\
\hline $\begin{array}{c}\text { Category name } \\
\text { of financial } \\
\text { assets }\end{array}$ & $\begin{array}{c}\text { Financial assets measured at the fair } \\
\text { value whose changes are included in the } \\
\text { current profit and loss }\end{array}$ & $\begin{array}{c}\text { Financial assets measured at the fair } \\
\text { value whose changes are included in the } \\
\text { current profit and loss }\end{array}$ \\
Account setting & $\begin{array}{c}\text { Tradable financial assets-changes in cost } \\
\text { or fair value }\end{array}$ & $\begin{array}{c}\text { Tradable financial assets-changes in cost } \\
\text { or fair value }\end{array}$ \\
\hline
\end{tabular}


financial instruments of companies. According to the new standard, the classification of financial assets should be disclosed and displayed in the balance sheet and income statement [3]. In order to allow the stakeholders and relevant supervisors to make decisions and read better, the company needs to write comments for the associated risks as much as possible. The specific impacts are as follows:

1) Impact on the balance sheet

From the perspective of accounting subjects, especially financial institutions, the application of the 3-category classification method reduces accounting subjects, defines the classification of financial assets, and makes the preparation of balance sheet simpler [4]. Through more standardized determination of the classification of financial assets, in the balance sheet, the true change of the fair value of the company included in other comprehensive income is reflected by the subject of "other comprehensive income". The holding consciousness is not changed according to the intention of the managers to make the surplus management, so as to include the change of fair value which should be included in the current profit and loss in other comprehensive income. Therefore, the 3-category classification method can provide users with accounting information with higher quality.

2) Impact on the income statement

In the old accounting standard, many financial assets are classified as "available-for-sale financial assets", so that a lot of changes in the fair value which are originally included in the current profit and loss are included in other comprehensive income of the company. The traditional income statement cannot reliably reveal the relevant conditions of the company, and the assessment and monitoring of the financial performance of the main body cannot be completely based on the income statement. However, under the new accounting standard, the equity instrument investment is calculated according to the fair value, which will lead to the corresponding increase in the measurement width of the fair value of some enterprises and the increase of financial assets accounted by the income statement. At the same time, the corresponding accounting treatment will be more comprehensive and perfect, and it will help to measure the financial performance of the main body with the income statement.

\subsection{Other Impacts of the Reclassification of Financial Assets}

1) Effectively prevent fraud

In the old accounting standard, financial assets are classified by the holding purpose. There are subjective factors in the classification and measurement of financial assets of a company, which is not objective. Managers can adjust the classification of financial assets by using the optional accounting policies to change the profit rate, which is more likely to cause financial fraud.

After the reclassification of financial assets, financial assets are classified by cash flow characteristics of the contract and the enterprise management mode. The standard requires that the accumulated changes in the fair value included in 
other comprehensive income should not be carried forward and included in the current profit and loss, which reduces the scope of control of a company. The reclassification uses the prospective application method to account for financial assets. The gains, losses and interests which have been recognized in the past can't be adjusted any more, which shows the prudence of accounting information.

2) Define the classification of financial assets

Before the reclassification, financial assets are divided into four categories with the four-category classification method. For available-for-sale financial assets, when a financial asset can be classified as available-for-sale financial assets when it does not have the conditions of the first three kinds of classification. It is not operable in practical work, and cannot correctly, effectively and reasonably make the accounting treatment by classification, which is easy to lead to misunderstanding of relevant accounting personnel. After reclassification, financial assets are divided into three categories. All kinds of financial assets are defined more clearly, the actual operability is improved and the essential attributes of financial assets are followed.

3) Guarantee the authenticity of accounting information

Under the old standard, the classification of financial assets is based on the intention of the holder. The managers require classifying financial assets by comprehensive risk management, investment decision-making and other factors [5]. If you want to change the company's financial conditions, provide false information and exaggerate the true performance of the company, you only need to ask the managers to change the purpose of holding the financial assets. In addition, under the current standard, a variety of classification conditions and complex initial measurement classification make it easier for accountants to make wrong classification in the process of operation. In the new accounting standard, financial assets are classified on the new basis, and there is a clear explanation for the basis in the new standard. It is longer easy to cause the problem of misclassification. A company should recognize the business model of financial assets according to the objective facts and should use it at will or distort it. In order to realize the prudence of accounting information, the loss incurred in the current period cannot be deferred in the next period.

In the current standard, the actual operation is limited greatly, even if financial assets are allowed to be between the fair value and the amortized cost. In the new standard, the scope of reclassification has been expanded. As long as the corresponding conditions are met, financial assets can be reclassified, and the loan should be consistent and equal.

\section{Enlightments Brought after the Reclassification of Financial Assets}

The new standard has simplified the classification, and improved the accuracy and authenticity of accounting information, but there are still some defects in its classification. Compared with the old standard, there are specific guidelines 
for the classification of financial assets in the new standard. Under the new standard, the management needs to consider the internal and external environment changes comprehensively, and make corresponding decisions through external confirmation, rather than relying solely on their own views, which reduces the freedom and diversity of the use of accounting information, thus reducing the possibility of making mistakes in the decision-making process of employees.

\subsection{The Identification of Specific Judgment Rules of Business Model Is Still Subjective}

Compared with the old accounting standard, the classification of financial assets under the new accounting standard is more principled and rational. However, at the same time, the classification is made through the business model test, and there is no specific objective evaluation standard and no corresponding identification guide for business model in the accounting standard, so that the accountants will have many judgments and subjective factors in the process of actual operation.

\subsection{The Measurement of Fair Value Is Uncertain}

Under the new accounting standard, the equity instruments are measured with the fair value. Market value method and similar item method are used to determine the fair value in China. In theory, the fair value comes from two factors: market and future cash flow discount. The scope of application of cash flow discount is wide, but its prediction is based on the stable development of the existing environment. At present, the capital market in China is not mature, and there is inevitably subjective intervention in the evaluation of expected discount rate of cash flow, estimated cash flow and final value. This will lead to the error between the fair value data and the actual situation, and reduce the reliability of the fair value information.

\subsection{It Will Take Some Time to Popularize and Apply the New Accounting Standard}

At present, the concept of classification of financial assets of most companies in Chinese mainland is still the four-category classification, rather than the three-category classification under the new accounting standard. Under the new accounting standard, the classification of financial assets needs more detailed and in-depth professional judgment. There is a lack of professional, systematical, careful and comprehensive learning of the newly issued accounting standard in China. At present, there is a lack of professional skills of actual operators. The cultivation mode of accounting innovation talents in China needs to be reformed. Now we need a new talent cultivation mode. Therefore, the application and promotion of the new accounting standard still needs time in China, and the promotion of the new standard cannot be completed immediately. 


\section{Epilogue}

This paper first describes the urgent need for the revision of accounting standards caused by the change of social environment in China, and points out that China has revised the accounting standards in 2017; then, it makes a specific description of the contents before and after the reclassification of financial assets according to the revised standards, and it also discusses the actual application of the reclassified financial assets in the form of cases. Secondly, it analyzes the advantages of financial assets in preventing fraud, clarifying classification and ensuring authenticity compared with the old accounting standards after reclassification. Finally, it explains the thinking after reclassification of financial assets. I hope that through the writing of this paper, we can deepen our understanding of the reclassification of financial assets under the new accounting standards, and speed up the implementation of the new standards in China.

\section{Conflicts of Interest}

The author declares no conflicts of interest regarding the publication of this paper.

\section{References}

[1] Wu, B.Z. and Lin, Z.Y. (2018) Exploration and Analysis on the Classification of Financial Assets. Economic Research Guide, No. 30, 89-90+94.

[2] Zhu, F. (2018) Change in the Classification and Measurement of Financial Assets and Their Implementation. Times Finance, No. 14, 82-83+85.

[3] Wang, C. (2018) Research on the New Financial Instrument Standard. International Business Accounting, No. 1, 71-72.

[4] Tong, L., Wu, Y.J., Ling, X., Wang, Z.X. and Chen, J. (2017) Research on the Differential Accounting Treatment of Non-Standard Investment. Finance, No. 12, 25-33.

[5] Wu, F.H. (2018) The Impact of the Implementation of the New Accounting Standard of Financial Instruments on Commercial Banks in China. Finance, No. 2, 54-62. 